Venesa Stanić

Nikša Fafandjel

Tin Matulja

http://dx.doi.org/10.21278/brod68303

ISSN 0007-215X

eISSN 1845-5859

\title{
A METHODOLOGY FOR IMPROVING PRODUCTIVITY OF THE EXISTING SHIPBUILDING PROCESS USING MODERN PRODUCTION CONCEPTS AND THE AHP METHOD
}

UDC 629.5.081

Original scientific paper

\begin{abstract}
Summary
In recent years, shipyards have been facing difficulties in controlling operational costs. To maintain continual operation of all of the facilities, a shipyard must analyze ways of utilizing present production systems for assembling interim vessel products as well as other types of industrial constructions. In the past, new machines continuously improved shipbuilding processes, including software and organizational restructuring, but management continued to search for a modern technological concept that will provide higher productivity, greater profit and overall reduction in costs. In the article the authors suggest implementing Design for Production, Design for Maintainability and Group Technology principles using the Analytical Hierarchy Process (AHP) to apply to multi criteria decision making methods as an efficient tool for maintaining international competitiveness in the modern shipbuilding industry. This novel methodology is implemented through four phases. In the first phase, the present situation analysis is suggested for a real shipyard by establishing closest relations among production lines. The second phase presents a constraint analysis that must be evaluated when developing the design solution. The third phase involves generating a typical number of selected alternatives of the Design for Production, Design for Maintainability and Group Technology principles. In the fourth phase, the optimal design solution is selected using the Analytical Hierarchy Process (AHP) method. The solution incorporating this modern methodology will improve productivity, profit and lead to decreasing operational costs.
\end{abstract}

Key words: $\quad$ Modern production concept; Design for Production; Design for Maintainability; Group Technology; Analytics Hierarchy Process (AHP) method; 


\section{Introduction}

Shipyards have to increase productivity and efficiency in all aspects of the shipbuilding process, especially in terms of tracking operational costs in order to maintain competitiveness in the global shipbuilding industry. Reduction in labor costs and production time is the most important requirement of shipyard productivity, and a matter of special attention for any shipyard. Modern shipyards must provide a maximum level of quality and at the same time lower labor costs. Furthermore, the production process for assembling interim vessel products and other types of industrial constructions needs to be established. The aim of this paper is to present a methodology for the implementation of modern production concepts such as Design for Production, Design for Maintainability and Group Technology. The proposed methodology reduces risks and production costs. Shipyard production processes such as cutting, welding, faster handling of transport, are often subject to improvements when increased productivity is the expected result, but this approach requires large capital investments. The main consideration of shipyard management is to minimize expenses and convert insufficient profitability or even losses into favorable profitability. This is important if a shipyard plans to become competitive in the global market. Technological improvements of shipyard production processes require a complex decision making approach [1]. When adopting any changes, numerous requirements and constraints in the shipyard production process require analyzing. The major challenge of a shipyard is to review and make improvements in building technology and organizational aspects, leading to increased productivity. Reducing excessive unplanned man hours and shipbuilding time results in achieving expected profit and shipyard deadlines [2]. The goal is to reduce design and manufacturing costs by $25 \%-30 \%$, and best time production costs by $20 \%$ $30 \%$ [3]. Shipyard productivity is usually calculated in the design stage before signing the shipbuilding contract, when planned consumption materials and working hours are calculated. An important role in the total cost calculation is the proposed building technology and level of preoutfitting. This article presents an implementation of Design for Production, Design for Maintainability and Group Technology concepts where the Analytical Hierarchy Process (AHP) multi criteria decision making method was tested and verified in a case study. The selected decision making method has already been proven successful in shipbuilding production processes [4]. This will provide support to management in the adoption of production concepts.

\section{Background}

The first technological improvements began in the mid-1920s in a number of USA, European and Japanese industries [1, 5]. In the 1950s and 1960s, a revolutionary process was the monitoring and statistical control of the production process, and the results were presented in several publications [6]. The US Navy was the first to introduce these processes and in the 1980s, it announced plans to modernize existing resources and develop concepts for increasing design quality in building its new generation of ships [7]. The Group Technology concept is based on an idea of grouping elements using similarities. In the shipbuilding industry, Group Technology is based on dividing a ship into a number of blocks [5]. These blocks are built in parallel, including outfitting and painting. Apply this concept optimally does improve the production process. The outcomes are better communication between specialists, reduction of duplications and errors in the assembly process, shorter production time, and improved production planning and scheduling procedures. Group Technology is implemented in two steps: selecting interim parts and workflow of construction procedures. The Design for Production concept is defined as the deliberate act of designing a product to meet its specified technical and operational requirements and quality, so that production costs will be reduced through lower work content and simplification of the production process [8]. The principles of the Design for Production concept is possible to improve through appropriate evaluation of design of facilities, workshops, production processes, minimizing of the production parts, standardization of material types, minimizing lifting and handling, optimizing welding, 
minimizing assembly process according to shipyard standards, simplifying engineering and optimizing inspection and testing. The Design for Maintainability concept, aim for minimum maintenance and total cost reduction during ship production and the life cycle [1]. This concept must be introduced early in the design stages in an optimal way.

\section{Productivity evaluation criteria}

For the maximum effectiveness, productivity evaluation is recommended throughout all phases of the shipbuilding process. Output at every production phase is an input for the next phase, which can directly affect productivity improvements. Poor evaluation early in the design stage may lead to increased problems in production, and should be avoided. The serious productivity consideration should be performed early in the design phase. Productivity is defined as an output-input comparison. Input is measured in man hours $(\mathrm{MH})$ of total yard activities (production, design, procurement, shipyard activities), subcontractors who work continuously and part-time employees who work occasionally in the shipyard. Productivity in the shipbuilding industry is based on Compensated Gross Ton (CGT) and is presented as working hours per CGT [9, 10]. The methodology for improving the shipbuilding process involves the Design for Production, Design for Maintainability and Group Technology increase productivity and lead to a shorter time frame for building a ship. The methodology is implemented in several steps and depends on shipyard facilities, availability of workshop areas, the number of skilled employees and capacity for investing in the shipyard.

\section{Problem-solving discussion}

When preparing a new shipbuilding production concept, it is important to evaluate all limitations and constraints of the facilities, workshops, available areas, transportation routes, organization and level of employee education and their influence on the flow of the shipbuilding process. Value added activities (welding, forming, machining, processing, assembling, painting) and non value added activities (scrapping, sorting, storing, counting, moving, documentation transfer) need to be evaluated. For the successful implementation of the new concepts is very important good knowledge in decision making. Cooperation and understanding between designers, production planners and production experts pave the way to new concept implementation. The shipyard produces a roll-on roll-off (ROPAX) vessels, tankers, bulk carriers, heavy lift vessels and smaller cruisers. Currently shipbuilding market is experiencing a crisis, where only a small number of owners are ordering series of the ship, shipyard management is open minded about meeting the needs for other type of civil engineering projects for the construction industry, while making maximum use of shipbuilding facilities.

The shipyard case study evaluates three types of constructions produced in the shipyard downstream process: Ro-pax vessel hull block, weight abt. 296t, heavy lift hull block, weight abt.300t and subsea protection construction, popularly called Venice protection doors weight abt. 290t. The dimensions of the Ro-pax vessel hull block are abt.: $22 \mathrm{~m}$ long, $4.5 \mathrm{~m}$ height, $18 \mathrm{~m}$ width. The interim products include: 10 semi-automatically assembled medium panels, 61 automatically assembled micro panels, 11 robotically assembled micro panels and 15 manually assembled micro panels in the shipyard downstream processes. The dimensions of the heavy lift hull block are: abt. $26.5 \mathrm{~m}$ long, $26 \mathrm{~m}$ width and $2.15 \mathrm{~m}$ height. The interim products include: 5 semi-automatically assembled large panels, 122 automatically assembled micro panels and 32 robotically assembled micro panels. The dimensions of the subsea protection construction are: abt. $21 \mathrm{~m}$ long, $4.6 \mathrm{~m}$ height and $18.6 \mathrm{~m}$ width. The interim products include: 7 semiautomatically assembled medium panels, 61 automatically assembled micro panels, 11 robotically assembled micro panels and 15 manually assembled micro panels in the shipyard downstream processes. Fig. 1 shows a comparison analysis of this three types of construction. 


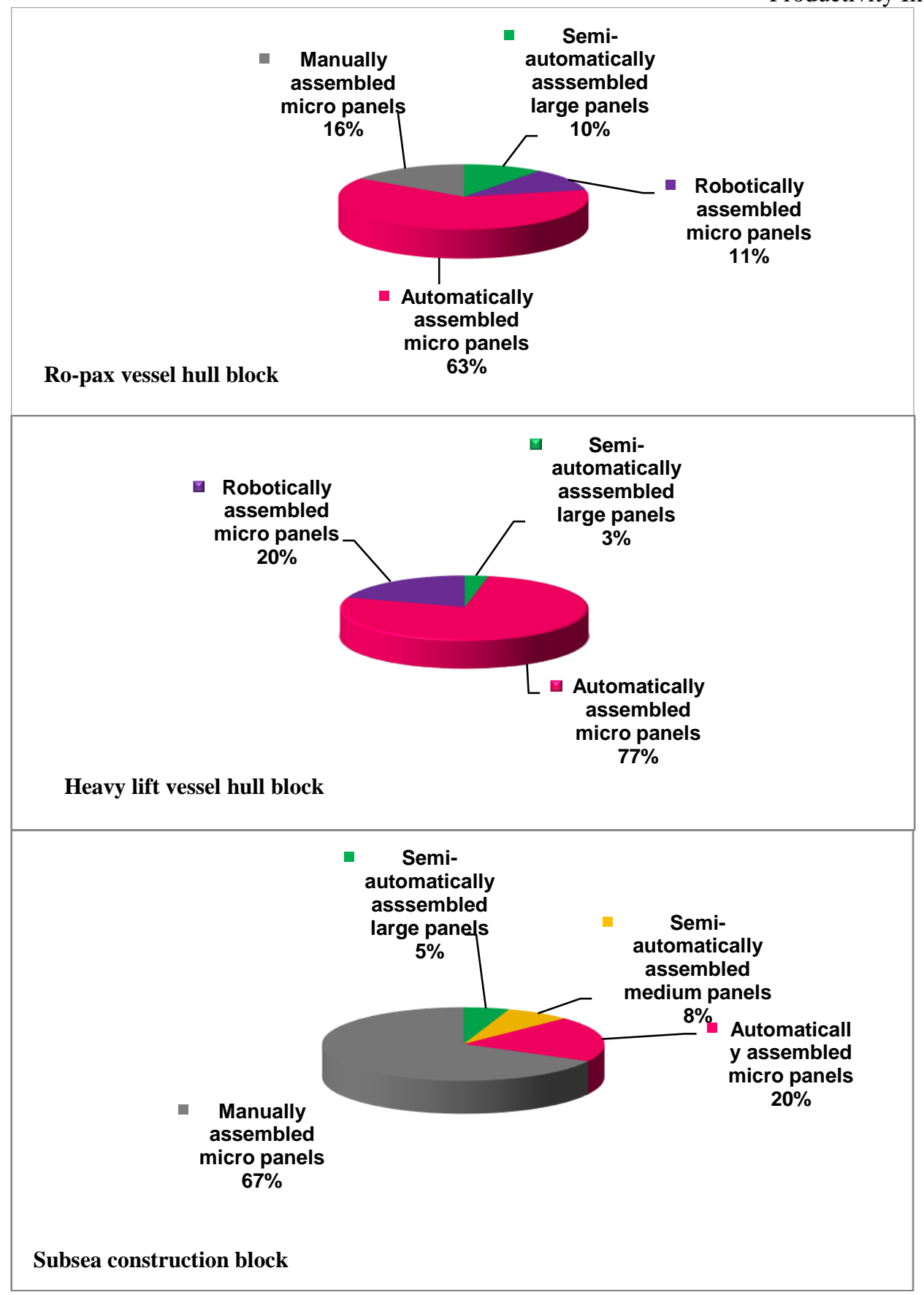

Fig.1 Comparison of processed materials

Basically, there are differences between processes, on the hull blocks there were all automatic welding processes, while on the Venice subsea construction there was a good number of manually welded structural elements. The shipyard workflow working hour is organized in daily shifts of 8 working hours. The month shipyard work period is 21 days, means 5 working days per week. Occasionally in case of short delivery timing, the daily working schedule is organized in two shifts of 8 hours working time in each shift. The ro-pax hull block production process was 35 working days, heavy lift hull block 38 working days, whereas the subsea construction production period was 55 days. 


\section{Implementation methodology based on the modern production concept}

In most of the shipyard changes and modifications in process starts as improved vision, but also were encouraged with new projects. This was the case with the case study shipyard. A new methodology for improving productivity of the existing shipbuilding process is based on conducting four phases to reduce risk and production cost.

The four phases are:

1. Identification of the closeness rating of selected shipyard facilities, processes and production lines,

2. Evaluation of the requirements and constrains analysis and influence on the possible design solution,

3. Identification of the selected alternatives,

4. Hierarchical modeling with an AHP method for selection of optimal solution,

\subsection{Phase 1}

In Phase 1, all necessary data of shipyard facilities, processes and production lines have been collected as follows:

- Selection of the shipyard production areas that are directly participating shipyard downstream process,

- Estimation of shipyard production facilities; length, width, height of the production lines,

- Number of employee and level of employee education involved in an implementation project,

- Tools and machines that will be used in production processes,

- Assessment of defined building technology taking into account the technological possibilities of the production process,

- Estimation of the horizontal and vertical transportation devices that will be used for the undisturbed shipyard downstream process.

Shipyard facilities and workshop layout shown on figure 2.

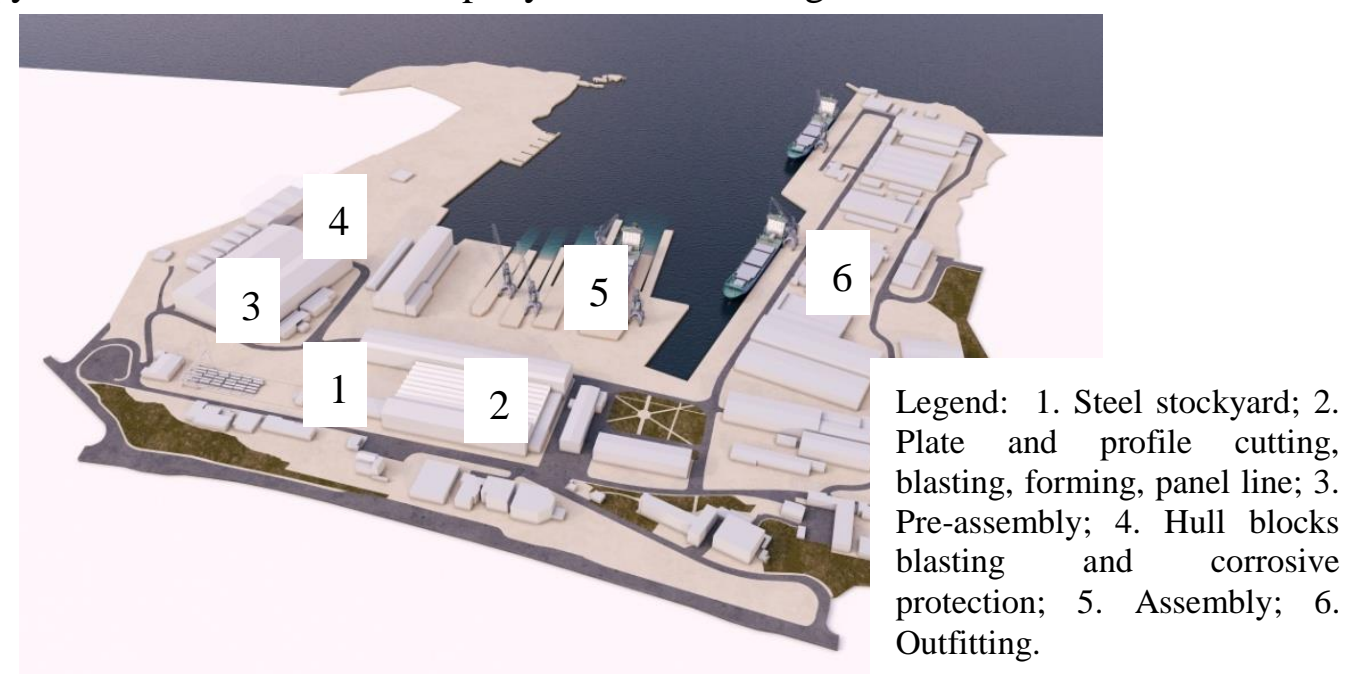

Fig. 2 Shipyard facilities and layout of workshops 


\subsection{Phase 2}

In the phase 2 , the constrains identification needs to be done when developing design solutions:

- Lifting capability of the cranes and transportation devices,

- Available workshops and their production capacities,

- Free storing space for loading the hull blocks in the shipyard area,

- Level of specialized skills of employees,

- Estimation of shipyard Electric Load Analysis,

- Implementation of different building technologies for several types of constructions,

- Usable area in closed workshop spaces for pre-outfitting of the hull block,

- Adequate operational program for 3D simulation and design modeling,

The four phases of the implementation proposed methodology for Pattern of Procedures are shown on Figure 3.

\subsection{Phase 3}

In the phase 3 will be done appointment of the implementing items as follows:

- Application of Design for Production, Design for Maintainability and Group Technology concepts,

- Professional training of employees and preparation of the organizational restructuring,

- Preparation of implementation methodology in selected shipyard areas,

- Energy improvement of the workshops and facilities for unhindered implementation of the proposed principles,

- Preparation of the sufficient number of the 3D implementation solutions,

- Preparation of the investment cycle for implementation items,

- Preparation of modified multilevel planning activities,

- ISO and "Just in Time" preparation and traceability of purchase materials and equipment.

\subsection{Phase 4}

In the Phase 4 will be evaluated the optimal implementation concept selected by multi criteria decision making method suggested below:

- Preparation of solutions, alternatives, criteria and limitations of the analysis,

- Evaluation of principles selected from the Design for Production, Design for Maintainability and Group Technology,

- Selection of acceptable project solutions by using the multi criteria decision making method,

- Selection and verification of the optimal solution using the sensitivity analysis (SA) method.

Table 1 shows the set of objectives to be achieved subject to the principles of modern production. 


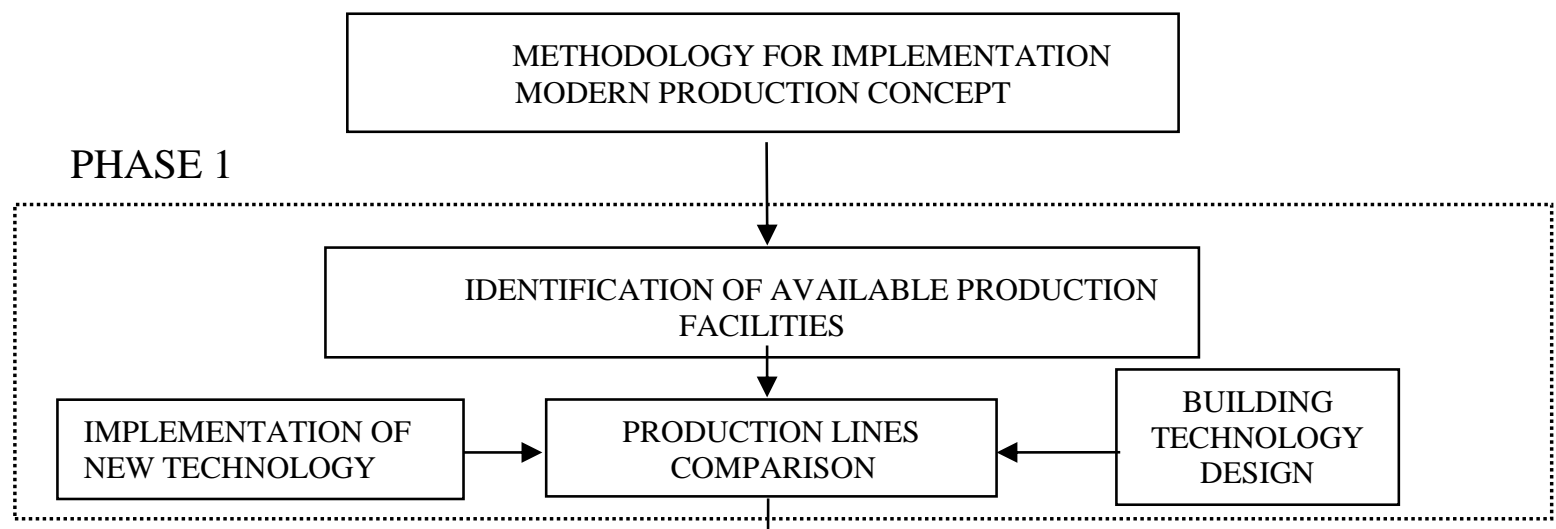

\section{PHASE 2}

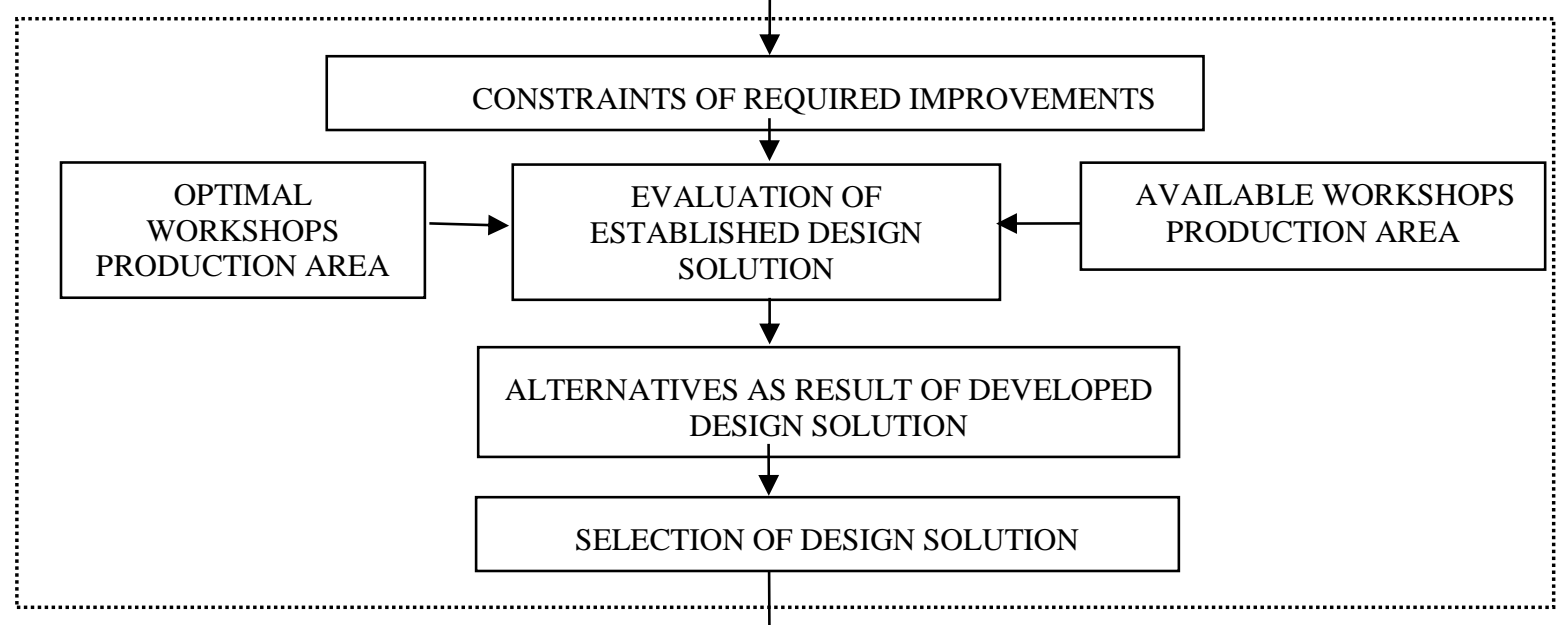

PHASE 3

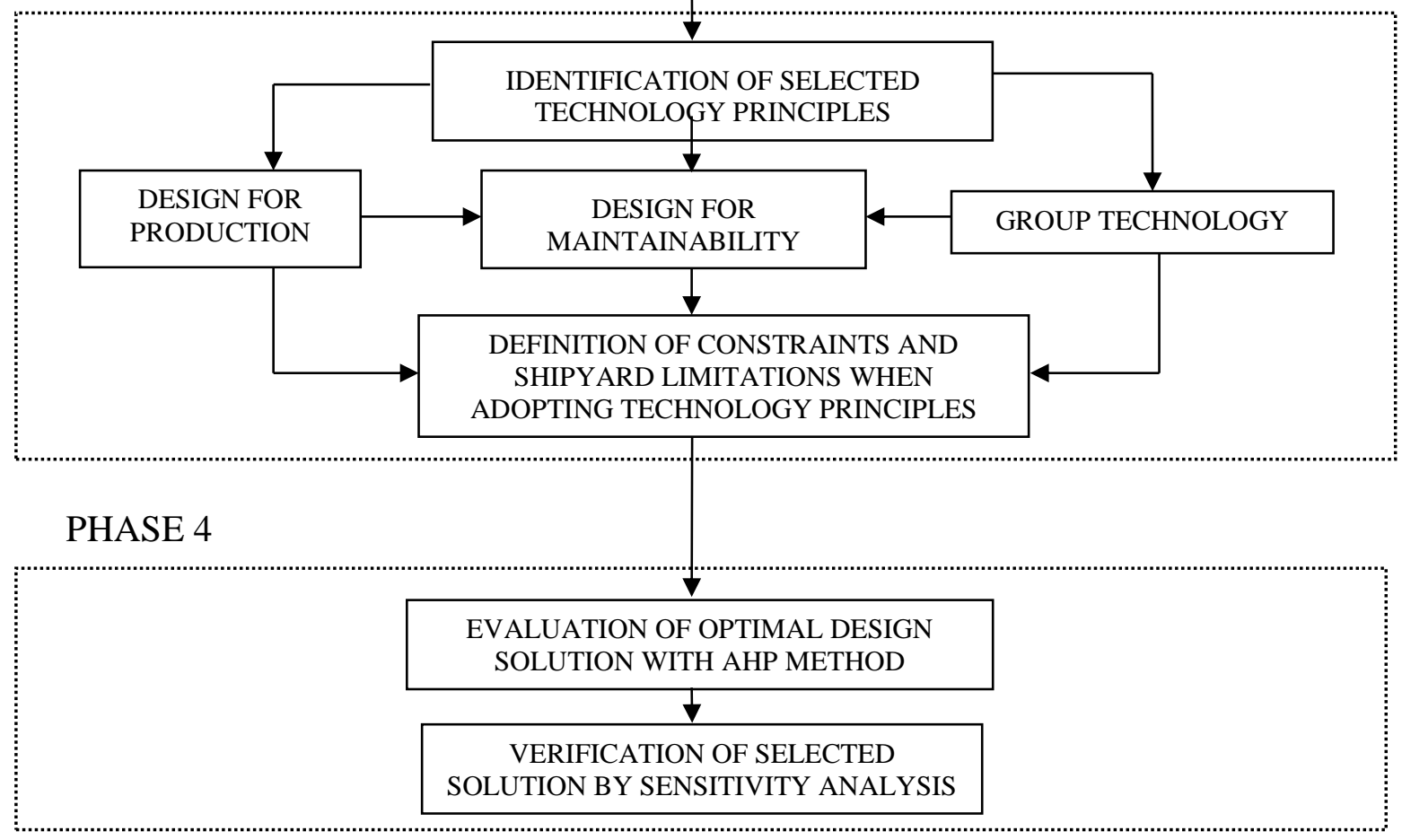

Fig.3 Proposed methodology for Pattern of Procedures 
Table 1 Objectives to be achieved

\begin{tabular}{|l|l|c|c|}
\hline & Area of implementation & $\begin{array}{c}\text { Reduction in } \\
\text { working hours }\end{array}$ & $\begin{array}{c}\text { Total savings in } \\
\text { working hours }\end{array}$ \\
\hline 1. & Improved design solution & $30-40 \%$ & $30-35 \%$ \\
\hline 2. & Shipyard facilities & $30-50 \%$ & $7-13 \%$ \\
\hline 3. & Material purchasing & $30-50 \%$ & $1-3 \%$ \\
\hline 4. & Welding techniques & $30-70 \%$ & $3-6 \%$ \\
\hline 5. & Tools, devices, robotics & $30-40 \%$ & $4-7 \%$ \\
\hline 6. & Tolerances, QC & & $4-8 \%$ \\
\hline 7. & Surface treatments & $25-40 \%$ & $1-3 \%$ \\
\hline 8. & Outfitting & $30-40 \%$ & $15-20 \%$ \\
\hline 9. & Overlap processes & & $10-15 \%$ \\
\hline \hline & Total savings & $25-40 \%$ \\
\hline
\end{tabular}

Principles of modern production concepts evaluated in the analyzed case study:

Design for Production:

1. Design plating with reduced number of stiffeners,

2. Structural design with balanced plate thicknesses,

3. Hull design with balanced stiffeners type (HP),

4. Design piping incorporating the same pipe bending radius,

5. Reducing pipeline and cable routes,

6. Design solution with respect to yard standards,

7. Optimized inspection and testing procedures;

\section{Design for Maintainability:}

1. Application of the increased stiffeners distance,

2. Reducing unnecessary lifting and handling of parts during construction,

3. Reducing the potential for ship repairing adequacies,

4. Minimize piping penetrations through transverse structure (elimination of reinforcements),

5. Design solutions with respect accessibility for installation and maintenance,

6. Preparation of the respectable number of 3D simulations;

\section{Group Technology:}

1. Grouping of similar hull blocks,

2. Grouping production processes with the similar production time,

3. Grouping of the specialist workers,

4. Grouping of hull blocks with the respect to the level of automation of the process,

5. Grouping of the hull blocks with the respect to same temporary devices,

6. Grouping of similar raw material dimensions. 


\section{Technology concept design selection}

For successful result of the proposed methodology the Analytical Hierarchy Process (AHP) method is suggested. The method can be used as an optimization application of the production solutions, but also for selecting proposed options that need to be taken into consideration or as a preliminary calculation analysis that needs to be achieved. The analytic hierarchy process is a structured technique for dealing with complex decisions [11]. It has particular application in group decision making, and assists decision makers in finding an optimal solution subject to the given criteria with respect to the constraints and limitations. In order to select an optimal balanced design solution, it is necessary to identify relevant constraints and limitations which solution has to consider optimizing.

Decisions to which the AHP can be applied include [11]:

- Choice - The selection of one alternative from a given set of alternatives, usually where there are multiple decision criteria involved,

- Ranking - Putting a set of alternatives in order from most to least desirable,

- Prioritization - Determining the relative merit of members of a set of alternatives, as opposed to selecting a single one or merely ranking them,

- Resource allocation - Apportioning resources among a set of alternatives,

- Benchmarking - Comparing the processes in one's own organization with those of other best-of-breed organizations,

- Quality management - Dealing with the multidimensional aspects of quality and quality improvement,

- Conflict resolution - Settling disputes between parties with apparently incompatible goals or positions.

A hierarchical model structurally consists of the following levels: a goal, criteria, subcriteria and alternatives (solutions) as shown in Figure 4. The goal is placed at the highest hierarchical level and it is not comparable to any other element of the hierarchical structure. At the first level, there are $k$ criteria which are compared to each other in pairs with respect to the directly superior element - the goal. The $k \cdot(k-1) / 2$ of comparisons is required. The same procedure is repeated for the next hierarchical level, all the way down to the last $r$ level (level of comparison), and by a comparison of all solutions with respect to the superior criteria, down to $r-1$ level (last level of comparison) is completed.

Each comparison of two (2) elements of the hierarchical model is done according to Saaty's scale of relative importance as shown in Table 2 [11].

At the top of the pyramid is the goal which is a reduction of the production time, and is the strongest tool for selecting criteria and alternatives. The selected criteria have come as a result of the production time and cost analysis prepared in the shipyard during 2014 and 2015. year [12]:

- Criterion 1: Investment cost $(€)$,

- Criterion 2: Producibility of design solution,

- Criterion 3: Obstruction of shipyard downstream process flow,

- Criterion 4: Production time (working hours),

- Criterion 5: Implementation period (months).

Figure 4 shows AHP hierarchical model. 


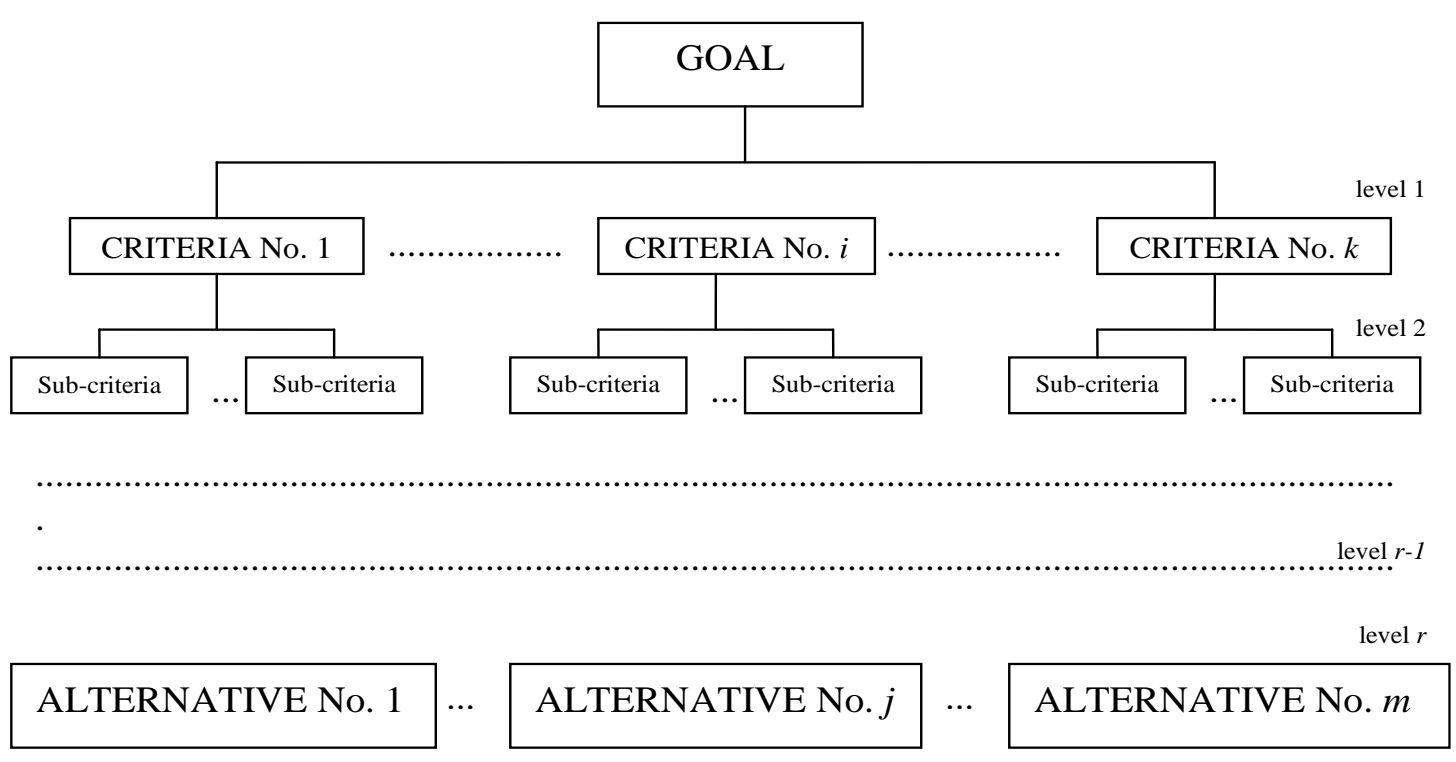

Fig.4 AHP hierarchical model, [11]

Table 2 shows Saaty's scale of relative importance.

Table 2 Saaty's scale of relative importance [11]

\begin{tabular}{|c|l|l||}
\hline $\begin{array}{c}\text { Intensity of } \\
\text { relative } \\
\text { importance }\end{array}$ & \multicolumn{1}{|c|}{ Definition } & \multicolumn{1}{c|}{ Explanation } \\
\hline \hline 1 & Equal importance & Two activities contribute equally to the objective \\
\hline 3 & $\begin{array}{l}\text { Moderate importance of } \\
\text { one over another }\end{array}$ & $\begin{array}{l}\text { Experience and judgment slightly favor one activity over } \\
\text { another }\end{array}$ \\
\hline 5 & Essential or strong & $\begin{array}{l}\text { Experience and judgment strongly favor one activity over } \\
\text { another }\end{array}$ \\
\hline 7 & Very strong importance & $\begin{array}{l}\text { An activity is strongly favored and its dominance is } \\
\text { demonstrated in practice }\end{array}$ \\
\hline $2,4,6,8$ & $\begin{array}{l}\text { Extreme importance } \\
\text { between two adjacent } \\
\text { judgments }\end{array}$ & $\begin{array}{l}\text { The evidence favoring one activity over another is of the } \\
\text { highest possible order of affirmation }\end{array}$ \\
\hline
\end{tabular}

The results of elements compared at hierarchy level and organized in matrix form are as presented in equations (2).

If $n$ elements are compared to each other with respect to the superior corresponding element at a higher hierarchical level, then, when comparing an $a$ element to $j$ element using a Saaty's scale of relative importance, the numerical coefficient $a_{i j}$ is determined and placed in its appropriate position in the matrix $A$ : 


$$
\mathbf{A}=\left[\begin{array}{ccccc}
a_{11} & a_{12} & \cdot & \cdot & a_{1 n} \\
a_{21} & a_{22} & \cdot & \cdot & a_{2 n} \\
\cdot & \cdot & & \cdot \\
\cdot & \cdot & & \cdot \\
a_{n 1} & a_{n 2} & \cdot & \cdot & a_{n n}
\end{array}\right]
$$

The inverse result value is placed in position $a_{j i}$ to maintain consistency in decision making. A detailed description of the AHP method can be found in [11].

\subsection{Identification of the modern technology concept closeness rating}

The AHP structures the decision problem using a multilevel hierarchy. The method requires the decision-maker to provide ratio scale comparisons between the different objectives, and calculates the vector of weights implied by the comparisons. Decision making provides a comparison between the alternatives, with respect to each objective, and implied ranking enable the decision maker to choose the best alternative.

The final ranking will depend on the decision maker's subjective perception, in this case this was a shipyard expert team that was included in the two years research (during 2014 and 2015. year) as preparation for building different types of the civil constructions and different types of the ships in the same period of the time. An interesting fact of the AHP method is that it allows inconsistencies in the comparison of the objectives. The fuzziness introduced by this flexibility increases the need for Sensitivity Analysis. A comparison of the selected proposed alternatives, according to the selected criteria can be evaluated respecting the closeness rating scale as shown in Table 3. Any disturbance of selected design solution has an influence on the standard production process. Weighting factors for the closeness rating are selected on a number scale from 5 to 0 and by using letters $\mathrm{U}, \mathrm{V}, \mathrm{I}, \mathrm{L}, \mathrm{A}$ and $\mathrm{N}$. The letter U implies the utmost importance; letter $\mathrm{V}$ very important, I important, L less important, A avoidable relationship, N not necessary. Table 3 presents closeness rating scale.

Table 3 Closeness rating

\begin{tabular}{|c|l|c|}
\hline Number & Closeness & Letter Code \\
\hline $\mathbf{5}$ & Utmost important & $\mathrm{U}$ \\
\hline $\mathbf{4}$ & Very important & $\mathrm{V}$ \\
\hline $\mathbf{3}$ & Important & $\mathrm{I}$ \\
\hline $\mathbf{2}$ & Les important & $\mathrm{L}$ \\
\hline $\mathbf{1}$ & Avoidable & $\mathrm{A}$ \\
\hline $\mathbf{0}$ & Not necessary & $\mathrm{N}$ \\
\hline
\end{tabular}

Table 4 presents a case study of 20 improvement items as probable solutions evaluated with respect shipyard research done during 2014 and 2015 year as shipyard preparation for building different types of ships and industrial constructions, but also with the respect to the shipyard constrains and limitations, which modern technology concept has to satisfy optimally [12]. 
Table 4 Proposed evaluated case study items

\begin{tabular}{|c|l|}
\hline No. & \multicolumn{1}{|c|}{ PROPOSED SOLUTION (PRODTME) } \\
\hline 1 & Processing of the structural elements according to the similar production requirements (SIMREQ) \\
\hline 2 & Design plating with reduced number of stiffeners (DESIGNP) \\
\hline 3 & Hull design with balanced stiffener type (HP) (STRSTIF) \\
\hline 4 & Design piping incorporating the same pipe bending radius (PIPEBEN) \\
\hline 5 & Structural design with a balanced plate thickness (STRUCTUR) \\
\hline 6 & Reduction of the piping penetrations through bulkheads (elimination of reinforcements) (PIPIEPEN) \\
\hline 7 & Grouping of similar hull blocks (flat or curved type) (SIMBLOC) \\
\hline 8 & Grouping of the hull blocks with the respect to usage of the same temporary devices (TEMPDEV) \\
\hline 9 & Reduction pipeline and cable routing (DESROUT) \\
\hline 10 & Grouping of the worker specialists (WORSPE) \\
\hline 11 & Grouping production processes with the similar production time (EQPROD) \\
\hline 12 & Reduction of the potential for ship repairing adequacies/ Maintenance reduction (SHIPREP) \\
\hline 13 & Usage of 3D modeling/Increasing design and processing simulations (3DPOR) \\
\hline 14 & Usage of standard design solutions (minimize worker training requirements) (STANDSOL) \\
\hline 15 & Usage as much as possible the yard standards (YARDST) \\
\hline 16 & Reduction of the unnecessary lifting and handling during construction (REDTR) \\
\hline 17 & Design solutions respecting accessibility for installation and maintenance (EASYAS) \\
\hline 18 & Design and implementation of the increased stiffeners distance (INCRSTIF) \\
\hline 19 & Reduction of the inspection and testing (MINISP) \\
\hline 20 & Reduction of the design solutions errors (DESISUP) \\
\hline
\end{tabular}

The closeness rating scale and the interdependence of the proposed solutions are shown in Table 5 as a relationship matrix, which takes into account optimal production flow and shipyard downstream process subject to minimal disruption of the production process. Some of the items are the result of costs caused by errors in previous designs and production processes which caused the over processing, while the others were created during the evaluation of shipyard possibility for design and processing of several types of construction (ships and industrial constructions) in the same period of time and in the same production processes (Shipyard building strategy 2014/2015).

\subsection{Proposed solution optimization}

As it was mentioned above, Criterion 1 analyzes the investment cost for each solution presented in Table 6. Criterion 2 analyzes producibility of the proposed solution ( $\mathrm{Y}$ - yes or $\mathrm{N}$ - no). Next, Criterion 3 evaluates obstruction of the shipyard downstream process flow ( $\mathrm{Y}$ as a yes or $\mathrm{N}$ for no). Criterion 4 evaluates production time (working days) calculating overlapping design and production capabilities of the shipyard. The Criterion 5 evaluates the implementation period in months for the necessary changes and modifications that need to be done in the shipbuilding process. This criterion taking into account all aspects of the shipbuilding process from design, purchasing, the level of workers education, the capacities of the shipyard production processes and the number and type of construction that need to be realized in the planning building period. 
Table 5 Relationship matrix

\begin{tabular}{|c|c|c|c|c|c|c|c|c|c|c|c|c|c|c|c|c|c|c|c|c|c|}
\hline & & 1 & 2 & 3 & 4 & 5 & 6 & 7 & 8 & 9 & 10 & 11 & 12 & 13 & 14 & 15 & 16 & 17 & 18 & 19 & 20 \\
\hline & & DESP & STRU & STRS & PIPB & DESR & YAST & MISP & INST & RETR & SHPR & STSO & PIEN & EASY & 3DPR & DESI & SIEQ & WOPE & SIMC & TEDV & EQPD \\
\hline 1 & DESP & $\diamond$ & I & $\mathrm{V}$ & $\mathrm{V}$ & $\mathrm{I}$ & $\mathrm{U}$ & $\mathrm{U}$ & $\mathrm{I}$ & $\mathrm{V}$ & $\mathrm{A}$ & $\mathrm{V}$ & $\mathrm{V}$ & $\mathrm{U}$ & I & $\mathrm{V}$ & $\mathrm{I}$ & $\mathrm{V}$ & $\mathrm{V}$ & A & I \\
\hline 2 & STRU & I & $\diamond$ & I & V & $\mathrm{U}$ & $\mathrm{U}$ & A & I & I & V & V & I & $\mathrm{U}$ & V & I & A & I & V & V & $\mathrm{V}$ \\
\hline 3 & STRS & V & I & $\diamond$ & I & $\mathrm{U}$ & $\mathrm{U}$ & I & V & V & $\mathrm{U}$ & I & V & V & I & $\mathrm{L}$ & $\mathrm{L}$ & I & I & V & V \\
\hline 4 & PIPB & $\mathrm{V}$ & $\mathrm{V}$ & I & $\diamond$ & $\mathrm{U}$ & $\mathrm{U}$ & $\mathrm{I}$ & I & I & I & $\mathrm{L}$ & $\mathrm{L}$ & $\mathrm{L}$ & $\mathrm{U}$ & $\mathrm{V}$ & I & A & I & $\mathrm{L}$ & I \\
\hline 5 & DESR & I & $\mathrm{U}$ & $\mathrm{U}$ & $\mathrm{U}$ & $\diamond$ & $\mathrm{U}$ & $\mathrm{V}$ & $\mathrm{V}$ & $\mathrm{V}$ & $\mathrm{U}$ & $\mathrm{U}$ & $\mathrm{U}$ & $\mathrm{V}$ & $\mathrm{V}$ & $\mathrm{V}$ & $\mathrm{U}$ & $\mathrm{V}$ & $\mathrm{V}$ & $\mathrm{U}$ & $\mathrm{V}$ \\
\hline 6 & YAST & $\mathrm{U}$ & $\mathrm{U}$ & $\mathrm{U}$ & $\mathrm{U}$ & $\mathrm{U}$ & $\diamond$ & $\mathrm{V}$ & $\mathrm{V}$ & I & $\mathrm{V}$ & $\mathrm{U}$ & $\mathrm{V}$ & $\mathrm{V}$ & $\mathrm{U}$ & $\mathrm{V}$ & $\mathrm{I}$ & $\mathrm{V}$ & $\mathrm{V}$ & $\mathrm{I}$ & $\mathrm{U}$ \\
\hline 7 & MISP & $\mathrm{U}$ & $\mathrm{A}$ & I & $\mathrm{I}$ & $\mathrm{V}$ & $\mathrm{V}$ & $\Delta$ & I & I & I & $\mathrm{V}$ & $\mathrm{V}$ & I & $\mathrm{I}$ & $\mathrm{U}$ & $\mathrm{U}$ & $\mathrm{V}$ & $\mathrm{I}$ & $\mathrm{V}$ & I \\
\hline 8 & INST & $\mathrm{I}$ & $\mathrm{I}$ & $\mathrm{V}$ & $\mathrm{I}$ & $\mathrm{V}$ & $\mathrm{V}$ & $\mathrm{I}$ & $\Delta$ & $\mathrm{V}$ & $\mathrm{V}$ & $\mathrm{V}$ & $\mathrm{I}$ & $\mathrm{I}$ & $\mathrm{I}$ & $\mathrm{A}$ & $\mathrm{I}$ & $\mathrm{V}$ & $\mathrm{V}$ & $\mathrm{I}$ & $\mathrm{I}$ \\
\hline 9 & RETR & $\mathrm{V}$ & I & $\mathrm{V}$ & I & $\mathrm{V}$ & I & $\mathrm{I}$ & $\mathrm{V}$ & 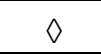 & $\mathrm{V}$ & $\mathrm{V}$ & $\mathrm{V}$ & I & I & $\mathrm{A}$ & $\mathrm{A}$ & I & I & $\mathrm{V}$ & $\mathrm{V}$ \\
\hline 10 & SHPR & $\mathrm{A}$ & $\mathrm{V}$ & $\mathrm{U}$ & $\mathrm{I}$ & $\mathrm{U}$ & $\mathrm{V}$ & $\mathrm{I}$ & $\mathrm{V}$ & $\mathrm{V}$ & $\diamond$ & $\mathrm{U}$ & $\mathrm{U}$ & $\mathrm{U}$ & $\mathrm{U}$ & $\mathrm{V}$ & $\mathrm{V}$ & $\mathrm{I}$ & $\mathrm{I}$ & $\mathrm{V}$ & $\mathrm{V}$ \\
\hline 11 & STSO & $\mathrm{V}$ & $\mathrm{V}$ & I & $\mathrm{L}$ & $\mathrm{U}$ & $\mathrm{U}$ & $\mathrm{V}$ & $\mathrm{V}$ & $\mathrm{V}$ & $\mathrm{U}$ & $\diamond$ & I & I & I & V & $\mathrm{U}$ & $\mathrm{U}$ & $\mathrm{V}$ & $\mathrm{V}$ & $\mathrm{V}$ \\
\hline 12 & PIEN & I & I & $\mathrm{V}$ & $\mathrm{L}$ & $\mathrm{U}$ & $\mathrm{V}$ & $\mathrm{V}$ & I & $\mathrm{V}$ & $\mathrm{U}$ & I & $\diamond$ & I & I & I & I & $\mathrm{L}$ & $\mathrm{L}$ & $\mathrm{L}$ & $\mathrm{L}$ \\
\hline 13 & EASY & $\mathrm{V}$ & $\mathrm{U}$ & $\mathrm{V}$ & $\mathrm{L}$ & $\mathrm{V}$ & $\mathrm{V}$ & I & I & I & $\mathrm{U}$ & I & I & $\diamond$ & $\mathrm{U}$ & $\mathrm{U}$ & $\mathrm{U}$ & I & $\mathrm{V}$ & I & $\mathrm{V}$ \\
\hline 14 & 3DPR & $\mathrm{U}$ & $\mathrm{V}$ & $\mathrm{I}$ & $\mathrm{U}$ & $\mathrm{V}$ & $\mathrm{U}$ & $\mathrm{I}$ & I & I & $\mathrm{U}$ & I & I & $\mathrm{U}$ & $\diamond$ & $\mathrm{L}$ & $\mathrm{L}$ & $\mathrm{I}$ & $\mathrm{V}$ & I & I \\
\hline 15 & DESI & I & I & $\mathrm{L}$ & $\mathrm{V}$ & $\mathrm{V}$ & $\mathrm{V}$ & $\mathrm{U}$ & $\mathrm{A}$ & $\mathrm{A}$ & $\mathrm{V}$ & $\mathrm{I}$ & I & $\mathrm{U}$ & $\mathrm{L}$ & $\diamond$ & $\mathrm{U}$ & $\mathrm{U}$ & $\mathrm{V}$ & $\mathrm{V}$ & $\mathrm{V}$ \\
\hline 16 & SIEQ & $\mathrm{V}$ & $\mathrm{A}$ & $\mathrm{L}$ & $\mathrm{I}$ & $\mathrm{U}$ & $\mathrm{I}$ & $\mathrm{U}$ & $\mathrm{I}$ & $\mathrm{A}$ & $\mathrm{V}$ & $\mathrm{V}$ & I & $\mathrm{U}$ & $\mathrm{L}$ & $\mathrm{U}$ & $\Delta$ & $\mathrm{I}$ & $\mathrm{I}$ & $\mathrm{I}$ & $\mathrm{I}$ \\
\hline 17 & WOPE & $\mathrm{I}$ & $\mathrm{I}$ & $\mathrm{I}$ & A & $\mathrm{V}$ & $\mathrm{V}$ & $\mathrm{V}$ & $\mathrm{V}$ & $\mathrm{I}$ & $\mathrm{I}$ & $\mathrm{U}$ & $\mathrm{L}$ & $\mathrm{I}$ & $\mathrm{I}$ & $\mathrm{U}$ & $\mathrm{I}$ & $\diamond$ & $\mathrm{V}$ & $\mathrm{V}$ & $\mathrm{V}$ \\
\hline 18 & SIMC & $\mathrm{V}$ & $\mathrm{V}$ & $\mathrm{I}$ & $\mathrm{I}$ & $\mathrm{V}$ & $\mathrm{V}$ & I & $\mathrm{V}$ & I & I & $\mathrm{U}$ & $\mathrm{L}$ & $\mathrm{V}$ & $\mathrm{V}$ & $\mathrm{V}$ & $\mathrm{I}$ & $\mathrm{V}$ & $\diamond$ & $\mathrm{L}$ & $\mathrm{L}$ \\
\hline 19 & TEDV & A & $\mathrm{V}$ & $\mathrm{V}$ & $\mathrm{L}$ & $\mathrm{U}$ & $\mathrm{I}$ & $\mathrm{V}$ & I & $\mathrm{V}$ & $\mathrm{V}$ & $\mathrm{V}$ & $\mathrm{L}$ & I & I & $\mathrm{V}$ & I & $\mathrm{V}$ & $\mathrm{L}$ & $\diamond$ & $\mathrm{V}$ \\
\hline 20 & EQPD & $\mathrm{I}$ & $\mathrm{V}$ & $\mathrm{V}$ & $\mathrm{I}$ & $\mathrm{V}$ & $\mathrm{U}$ & $\mathrm{I}$ & $\mathrm{I}$ & $\mathrm{V}$ & $\mathrm{V}$ & $\mathrm{V}$ & $\mathrm{L}$ & $\mathrm{V}$ & I & $\mathrm{V}$ & $\mathrm{I}$ & $\mathrm{V}$ & $\mathrm{L}$ & $\mathrm{I}$ & 0 \\
\hline
\end{tabular}


Table 6 shows ratio of solution items to established criteria.

Table 6 Ratio of solution items to established criteria

\begin{tabular}{|c|c|c|c|c|c|c|}
\hline \multicolumn{2}{|c|}{$\begin{array}{c}\text { SOLUTION } \\
\text { ITEMS }\end{array}$} & 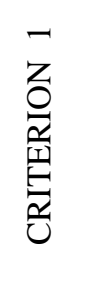 & 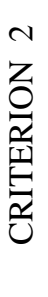 & 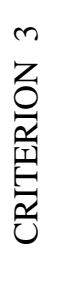 & 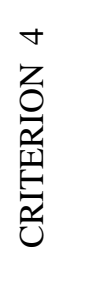 & 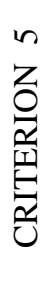 \\
\hline \multirow{20}{*}{ 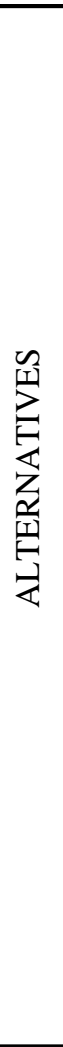 } & Solution 1 & 10000 & $\mathrm{Y}$ & Y & 100 & 1 \\
\hline & Solution 2 & 55000 & $\mathrm{Y}$ & $\mathrm{N}$ & 1008 & 12 \\
\hline & Solution 3 & 8000 & $\mathrm{Y}$ & $\mathrm{N}$ & 300 & 12 \\
\hline & Solution 4 & 45000 & Y & $\mathrm{N}$ & 40 & 6 \\
\hline & Solution 5 & 0 & Y & $\mathrm{N}$ & 0 & 4 \\
\hline & Solution 6 & 52000 & Y & $\mathrm{N}$ & 300 & 12 \\
\hline & Solution 7 & 5000 & $\mathrm{Y}$ & $\mathrm{N}$ & 300 & 6 \\
\hline & Solution 8 & 1000 & $\mathrm{Y}$ & $\mathrm{N}$ & 40 & 2 \\
\hline & Solution 9 & 20000 & $\mathrm{Y}$ & $\mathrm{N}$ & 300 & 12 \\
\hline & Solution 10 & 25000 & $\mathrm{Y}$ & $\mathrm{N}$ & 100 & 2 \\
\hline & Solution 11 & 0 & $\mathrm{Y}$ & $\mathrm{N}$ & 100 & 12 \\
\hline & Solution 12 & 5000 & $\mathrm{Y}$ & $\mathrm{N}$ & 100 & 12 \\
\hline & Solution 13 & 5000 & $\mathrm{Y}$ & $\mathrm{N}$ & 250 & 12 \\
\hline & Solution 14 & 0 & $\mathrm{Y}$ & $\mathrm{N}$ & 100 & 6 \\
\hline & Solution 15 & 10000 & $\mathrm{Y}$ & $\mathrm{Y}$ & 50 & 2 \\
\hline & Solution 16 & 20000 & $\mathrm{Y}$ & $\mathrm{Y}$ & 100 & 2 \\
\hline & $\begin{array}{ll}\text { Solution } 17 \\
\end{array}$ & 10000 & $\mathrm{Y}$ & $\mathrm{Y}$ & 100 & 2 \\
\hline & Solution 18 & 5000 & $\mathrm{Y}$ & $\mathrm{Y}$ & 200 & 10 \\
\hline & Solution 19 & 20000 & $\mathrm{Y}$ & $\mathrm{Y}$ & 1008 & 2 \\
\hline & Solution 20 & 8000 & $\mathrm{Y}$ & $\mathrm{Y}$ & 500 & 2 \\
\hline
\end{tabular}

The AHP method allows a randomized ranking list of selected probable solutions that are evaluated and considered as approach to finding relevant and optimal results.

Overall priorities of the probable solutions are calculated by using an equation (3).

$$
\mathrm{P}_{\mathrm{i}}=\mathrm{A}_{1-\mathrm{i}} \cdot \mathrm{K}_{1}+\mathrm{A}_{2-\mathrm{i}} \cdot \mathrm{K}_{2}+\mathrm{A}_{3-\mathrm{i}} \cdot \mathrm{K}_{3}+\mathrm{A}_{4-\mathrm{i}} \cdot \mathrm{K}_{4}+\mathrm{A}_{5-\mathrm{i}} \cdot \mathrm{K}_{5}
$$

Based on determining priorities from $P_{1}$ to $P_{20}$, the solutions with the highest value were selected, and such solutions are considered optimal.

A presents alternative, whereas $\mathrm{K}$ represents the criteria.

Local and overall priorities of solution items are presented in Table 7. 
Table 7 Local and overall priorities of solution items

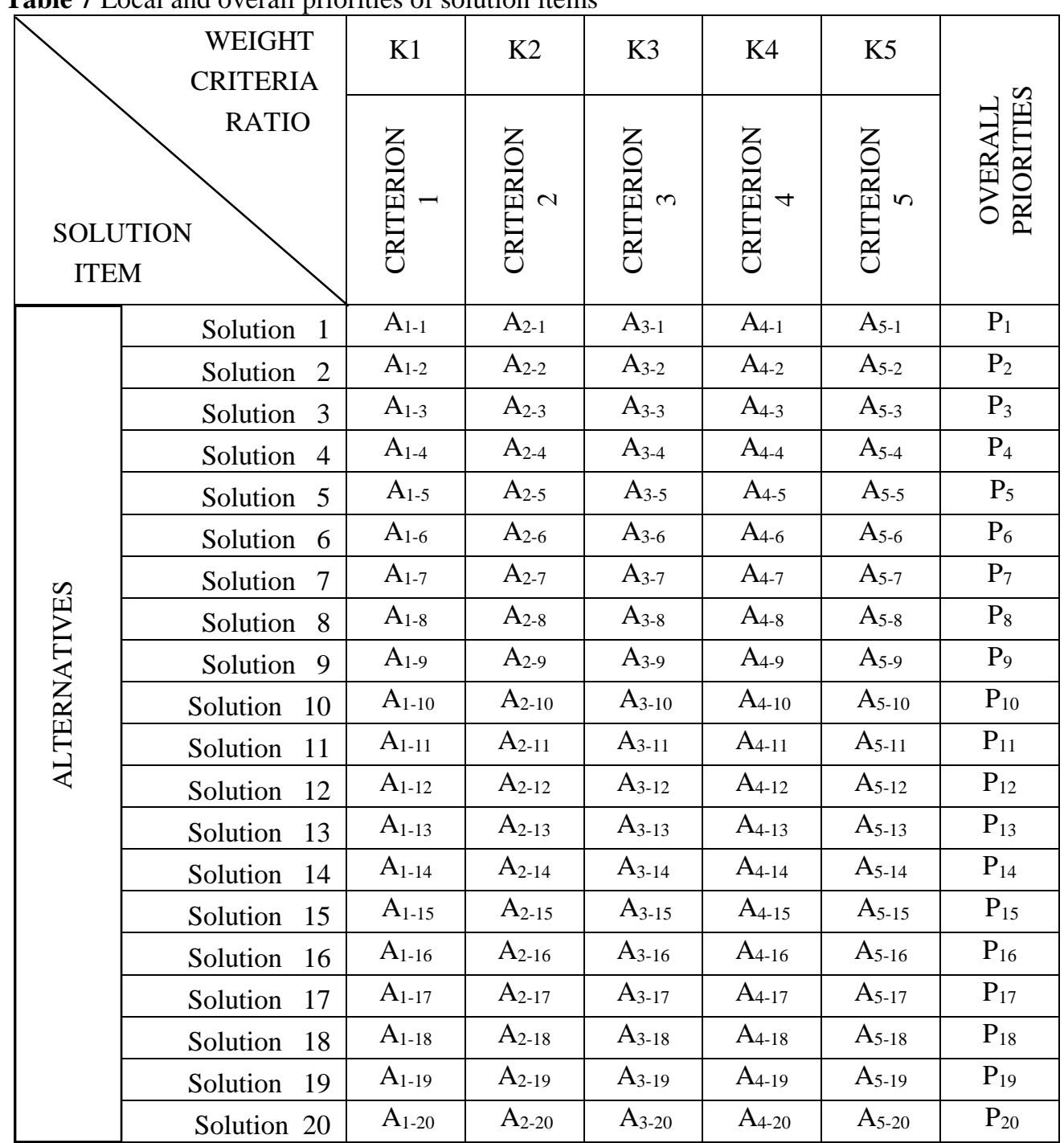

Within AHP Expert Choice software, local and overall priorities are found, as it was presented in table 7.

The random alternatives scale is presented in the Table 8 , arranged from the most to least important.

Within AHP Expert Choice software, for hierarchical modeling is presented ranking list of solution items, priorities presented in Figure 5. 
Table 8 Random alternatives scale

\begin{tabular}{|c|c|c|}
\hline Alternative & $\begin{array}{l}\text { PROPOSED SOLUTION ITEMS } \\
\text { (PRODTME) }\end{array}$ & $\begin{array}{c}\text { From most to least } \\
\text { important } \\
1 \text { (most) to } 20 \\
\text { (least) }\end{array}$ \\
\hline 17 & $\begin{array}{l}\text { Design solutions respecting accessibility for installation and maintenance } \\
\text { (EASYAS) }\end{array}$ & 1 \\
\hline 12 & $\begin{array}{l}\text { Reduction of the potential for ship repairing adequacies/ Maintenance } \\
\text { reduction (SHIPREP) }\end{array}$ & 2 \\
\hline 15 & Usage as much as possible the yard standards (YARDST) & 3 \\
\hline 7 & Grouping of similar hull blocks (flat or curved type) (SIMBLOC) & 4 \\
\hline 9 & Reduction pipeline and cable routing (DESROUT) & 5 \\
\hline 10 & Grouping of the specialist workers (WORSPE) & 6 \\
\hline 19 & Reduction of the inspection and testing (MINISP) & 7 \\
\hline 13 & $\begin{array}{l}\text { Usage of 3D product model/Increasing structural and process simulations } \\
\text { (3DPOR) }\end{array}$ & 8 \\
\hline 8 & $\begin{array}{l}\text { Grouping of the hull blocks with the respect to usage of the same } \\
\text { temporary devices (TEMPDEV) }\end{array}$ & 9 \\
\hline 2 & Design plating with reduced number of stiffeners (DESIGNP) & 10 \\
\hline 5 & Structural design with balanced plate thickness (STRUCTUR) & 11 \\
\hline 3 & Hull design with balanced stiffener type (HP) (STRSTIF) & 12 \\
\hline 4 & Design piping incorporating the same pipe bending radius (PIPEBEN) & 13 \\
\hline 11 & $\begin{array}{l}\text { Grouping production processes with the similar production time } \\
\text { (EQPROD) }\end{array}$ & 14 \\
\hline 16 & $\begin{array}{l}\text { Reduction of the unnecessary lifting and handling of parts during } \\
\text { construction (REDTR) }\end{array}$ & 15 \\
\hline 6 & $\begin{array}{l}\text { Reduction of the piping penetrations through transverse (elimination of } \\
\text { reinforcements) (PIPIEPEN) }\end{array}$ & 16 \\
\hline 14 & $\begin{array}{lllll}\text { Usage of standard design } & \text { solutions } & \text { (minimize } & \text { workers } & \text { training } \\
\text { requirements) (STANDSOL) }\end{array}$ & 17 \\
\hline 20 & Reduction of the design duplications (DESISUP) & 18 \\
\hline 18 & Design implementation of the increased stiffeners distance (INCRSTIF) & 19 \\
\hline 1 & $\begin{array}{l}\text { Processing of the structural elements according to the similar production } \\
\text { requirements (SIMREQ) }\end{array}$ & 20 \\
\hline
\end{tabular}

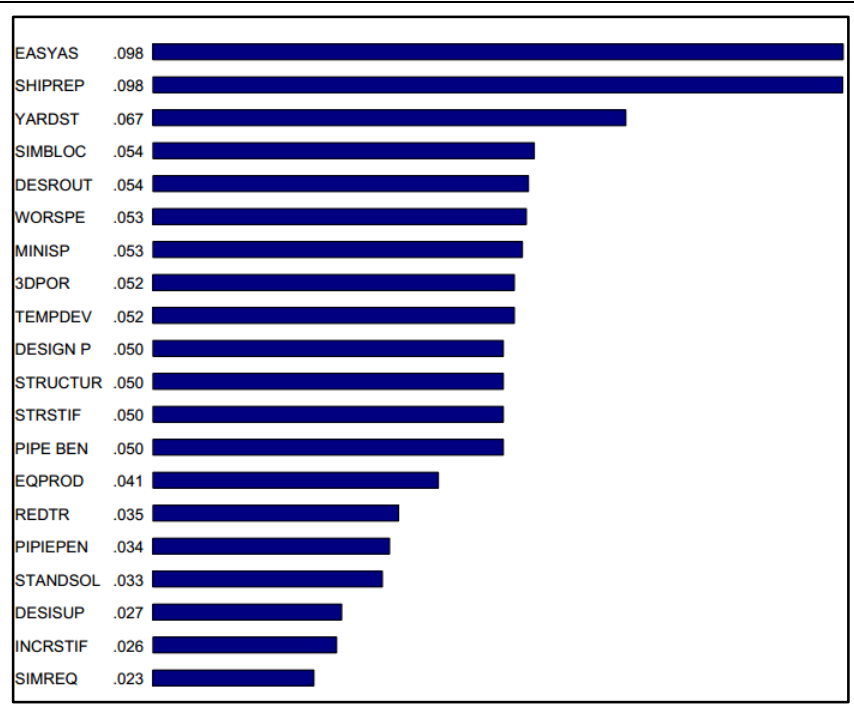

Fig.5. Overall priorities of solution items [AHP Expert Choice software] 


\section{Stability verification using Sensitivity Analysis}

Sensitivity Analysis is defined as the study of how uncertainty in the output of a model can be attributed to different sources of uncertainty in the model output [13]. The optimization software, Sensitivity analysis refers to understanding how the parameters and solution items of analyzing model influence the optimization goal result. Sensitivity Analysis examines the sensitivity of the results to changes in the priorities of the criteria. This is particularly important aspect of an AHP problem analysis, since results are based on subjective expert assessments. Sensitivity analysis can be performed from any level in the hierarchy; the software displays the sensitivity of alternatives to the priority of the criteria immediately below a user selected node. The flexibility is very useful for fine tuning the sensitivity analysis.

The Evaluation and Choice module provides five different graphical modes for performing sensitivity analysis:

- Dynamic,

- Performance (Figure 6),

- Gradient,

- Head to Head.

Each of these graphic modes provides a different viewpoint to a sensitivity analysis. Under any of these five modes, the user can easily manipulate criterion priorities and immediately see the impact of the changes (as a reflection in the ranking of alternatives).

Decision-making is an integral part of the operating management. For decision-makers can be useful to have an indication level of sensitivity when selection of alternatives changes in one or more of these values. There are certain things that help judgment of the sensitivity of the probability assumptions. One of the tools useful to analyze some of the problems is the Sensitivity Analysis.

Generally, there are two types of Sensitivity Analysis as follows [14]:

- Analytical SA: for well defined systems and problem solving using partial derivation presented with Equitation (4),

$$
\mathrm{S}_{x}{ }^{F}=\partial \mathrm{F} / \partial \mathrm{x}
$$

where $S_{x}$ is the sensitivity function (change intensity) of the goal function $F$ with respect to changes in the parameter $x$.

- Empirical SA: used for experimentally defining variation parameters based on the optimal solution.

This SA type is used as the complex system solving method. In the solving complex shipbuilding process doubts the Expert Choice software was used [15, 16].

Based on determining priorities from $P_{1}$ to $P_{20}$ solution with the highest value is considered as the optimal one. As a conclusion, the empirical Sensitivity Analysis (SA) is suggested for various combinations of input data if the suggested rank list of design solutions is stable. Its purpose and results as follows:

- Determination of the optimal solution stability,

- Accessibility and simplicity of the hierarchical model,

- Identification of a new hierarchy model parameter,

- Definition and determination of critical hierarchical model parameters.

In applying the selected optimal design solution is verified as stable and therefore as an optimal [13]. In making a decision on the proposed design solution, Expert Choice software was used. [16].

A performance Sensitivity graph of the model is presented in Figure 6, where data for each of the analyzed items is shown with the different color. On the x-axis, it can be seen five criteria 
used in the model, and on the right-hand-side y-axis it can be seen the overall scores of all the analyzed items (alternatives). The sum of these overall items is equal to 1 , in accordance with the AHP methodology.

The terms INVCOST, PRODDESG, OBSTPROC, PORDTIME, IMPLEMPE refers to the nodes immediately below the goal. The left $y$-axis represents the relative priority of each criterion (as synthesized from the expert pair-wise comparisons). The right $\mathrm{x}$-axis represents the overall priority of each alternative (with the OVERALL axis showing the overall priority of each alternative). The vertical bars represent the derived relative priorities of each criterion.

Dragging of any of the vertical bars causes an immediate change in the priority of each alternative. The outputs for any combination of the modes can be tiled so that they may be viewed simultaneously. The graph on the Figure 6 illustrates the graphic interface of the performance Sensitivity Analysis as applied to a site selection problem.

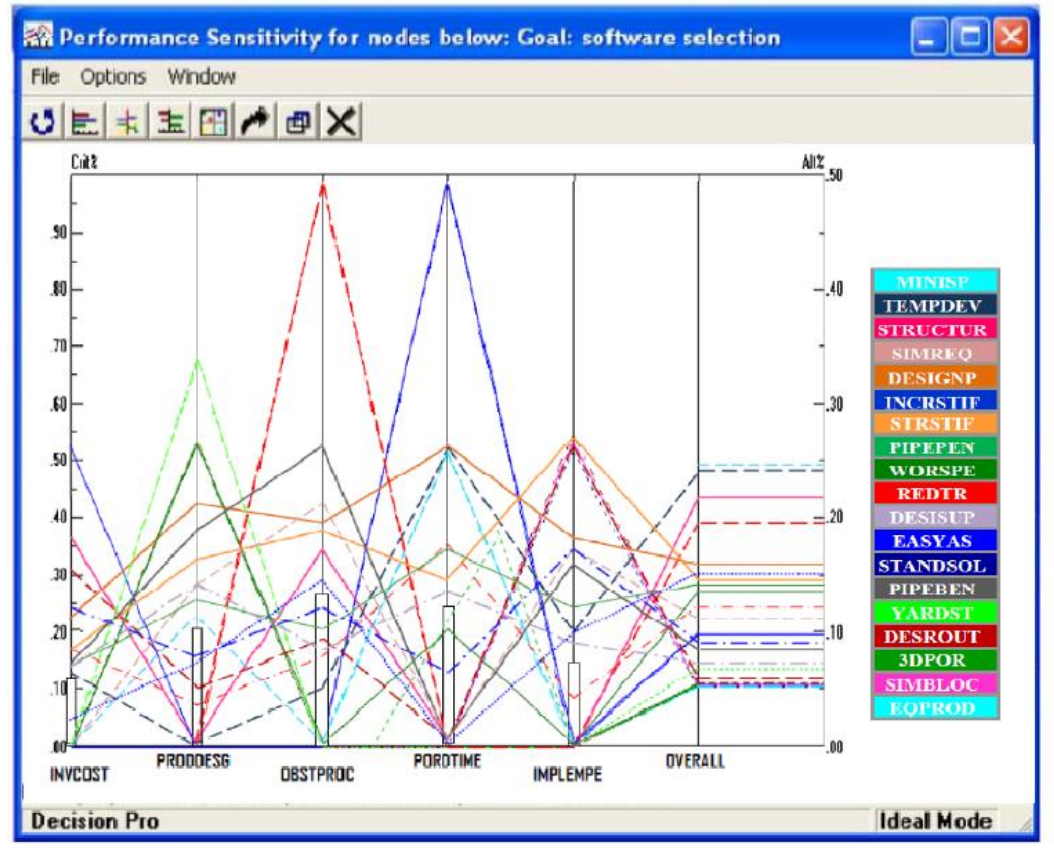

Fig.6. Performance of Sensitivity Analysis

The proposed methodology led to selecting the optimal design solution, when overall evaluation is finished to selected solution no. 17 .

The analysis took into account the complexity of the shipbuilding design and production process respecting shipbuilding strategy for producing a different type of the construction (ships and civil construction) in the same production process, respecting shipyard facilities, organizational restructuring and investment cost for the purpose of preparing a modern production concept.

\section{Conclusion}

The global shipbuilding industry faces continual improvements, reorganization and restructuring processes that result in increasing productivity and reducing of ship production costs. Modern production concepts such as Design for Production, Design for Maintainability and Group Technology can be applied in any production process. The methodology is applicable within four phases for an optimized implementation of the mentioned modern production concepts. An expert approach and using the AHP method facilitates in reaching a final production mix. Firstly, the main precondition is an expert approach subject to a detailed analysis of the considered process, detection of inadequacies and demand spots, followed by a 
Productivity Improvement...

recommended list of potential improvements and organizational changes that could very well increase net profit and accelerate production and delivery. To this end, a large number of proposed solutions take into account the selected criteria and constraints that generate alternatives which in turn are to be subsequently analyzed. This process was tested on a real shipyard. The optimal solution is the final version selected using the AHP method and verified by Sensitivity Analysis. Finally, proposed methodology delivered the ranking list of topics that need improvements such as: production organization, design solutions and large use of software solutions for design and production process in early design stage to have an overall picture of the future production process. Furthermore, using proposed methodology; other crucial points were detected, such as: unnecessary design and production errors, lack of efficient flow of information and materials. The proposed methodology can be an applicable model for other shipyards which are oriented towards building special ships and civil engineering projects. The authors recommend for future research a more detail analysis of the assembly processes, steel preparation processes and outfitting workshops.

\section{Acknowledgement}

This research is supported by funds from the support research at the University of Rijeka for the project “An Improved Methodology of the Design Process in Ship Construction, „no. 13.09.1.1.06.

\section{REFERENCES}

[1] Dlugokecki V., Hepinstall L., 2014. "Design for [Fill in the Black]", (mt) Marine Technology, Publication of The Society of Naval Architecture and Marine Engineers, ISSN 2153-4721,

[2] Lamb T., 1986. "Engineering for Ship Production“, SNAME, University of Michigan, Ann Arbour, Michigan, USA.

[3] Caprice J.D., Bair D., Losseau N., Rigo P., 2006."Minimization of Production Cost by use of an Automatic Cost Assessment Method and Simulation", University of Liege, Belgium.

[4] Matulja, T.: "Hierarchical Modeling as Basis of the Methodology for Shipyard Production Layout Design“, PhD Thesis, Faculty of Engineering, Rijeka, 2009.

[5] Mosaad M.A., Abdelghany R.R., Sayed A.D., 2014. "On the productivity of shipyards when adopting group technology concept", Department of Naval Architecture and Marine Engineering, Port Said University, Egypt.

[6] The National Shipbuilding Research Program, 1989. "Productivity in Ship Design", US Department of Navy Carderock Division, 1989 Ship Production Symposium, USA.

[7] Cummiskey W. J., 1990. "United States Commercial Shipbuilding Productivity An International View" Naval Postgraduate School, Monterey, California, USA.

[8] Larkins D., 2007. "Practical Application of Design for Production", Ship Construction Software INC, Canada.

[9] OECD, 2007. Directorate for Science, Technology and Industry (STI), Council Working Party on Shipbuilding "Compensated Gross Ton (CGT) System" USA.

[10] Wilkins J.R., Thompson H. D., 1992. "Evaluating the Producibility of Ship Design Alternatives", SNAME, Ship Production Symposium, New Orleans Hyatt, USA.

[11] SAATY, T. L., 1980. The Analytic Hierarchy Process“, ISBN: 0-07-054371-2. McGraw-Hill, Inc. USA.

[12] Stanic V., Kolic D., Fafandjel N., 2015. "Production Engineering and Management “, 5th International Conference on Production Engineering and Management, Trieste, Italy.

[13] Saltelli A., Ratto M., Andres T., 2008. "Global Sensitivity Analysis. The Primer", John Wiley and Sons.

[14] SNAME, University of Michigan, Ann Arbour, Michigan, USA.

[15] Winston, W. L.: "Operations Research: Applications and Algorithms", Publisher: Duxbury Press; 4 edition, ISBN: 0534380581. 2003.

[16] Expert Choice, inc.: "Expert Choice software 11", Arlington, VA, USA, 2004. 


\section{Nomenclature}

3DPOR - Usage of 3D Production Model

$A_{l i} \quad$ - local priority of the $i$-class alternative regarding criterion 1

$A_{2 i} \quad$ - local priority of the $i$-class alternative regarding criterion 2

$A_{3 i} \quad$ - local priority of the $i$-class alternative regarding criterion 3

$A_{4 i} \quad$ - local priority of the $i$-class alternative regarding criterion 4

$A_{5 i} \quad$ - local priority of the $i$-class alternative regarding criterion 5

AHP - Analytic Hierarchy Process

$a_{i j} \quad$ - Saaty's intensity of relative importance

CGT - Compensated Gross Ton

DesignP - Design Plating with Reduced Number of Stiffeners

Desisup - Reduce Design Duplications

Desrout - Design shortened pipeline and cable routes

Easyas - Design of Easy Accessibility

Eqprod - Grouping of Equal Production Time

Implpe - Implementation Period

Incrstif - Design for Stiffeners Distance

Invcost - Investment Cost

$K_{1-5} \quad$ - Criteria

Minisp - Minimize Inspection and Testing

Obproc - Obstruction of Downstream Process

$P_{i} \quad$ - Overall priority of $i$-class

PipeBen - Design of Pipe Bending Radius Type

Pipiepen - Minimize Penetrations through Structure

Prodtme - Production Time

Prodesg - Producibility of Design Solution

Redtr - Reduction of Unnecessary Lifting

SA - Sensitivity Analysis

Shiprep - Reduction of Ship Repair Error

Simbloc - Grouping of Hull Block with Similarities

Simreq - Grouping Of Processes with similarities

Standsol -Using of Standard Technical Solution

Strstif - Structural Design of Equal Stiffeners

Structur - Structural Design of Equal Plating

Tempdv - Grouping Similar Hull Blocks with same devices

Worspe - Grouping of Workers Specialist

Yardst - Design solutions by using Yard Standards

Submitted: 04.04.2017. Venesa Stanić, venesa.stanic@ brodosplit.hr, Leading Designer Shipyard "Brodosplit", Put Supavla 21, 21000 Split

Accepted: 05.04.2017. Nikša Fafandjel, niksaf@ riteh.hr, Professor

Tin Matulja, tin.matulja@ riteh.hr, Assistant Professor

Naval Architecture and Ocean Engineering Department,

Faculty of Engineering, University of Rijeka, Vukovarska 58, Rijeka 